\title{
Un análisis sobre la excepción de reproducciones electrónicas en bibliotecas del artículo 7 I K de la Ley I7.336
}

\author{
An Exploratory Analysis \\ of the Exceptions Regarding the Electronic Reproductions \\ on Libraries set in Article $71 \mathrm{~K}$ of Law 17.336
}

VICENTE GRUBSIC Y JOAQUÍN CASTRO

Egresado y estudiante de Derecho, Chile

RESUMEN La Ley I7.336 incorporó, en su última modificación, un nuevo catálogo de excepciones. Destacan aquellas cuyo objeto es promover y legitimar la actividad de bibliotecas y archivos. En particular, la excepción del artículo 7 I K se refiere a la posibilidad de vincular el quehacer de las bibliotecas y archivos con las nuevas tecnologías de la información, permitiendo que el acceso a las obras aumente de forma significativa. Este trabajo busca interpretar de la manera más completa posible la mayor parte de los conceptos indeterminados de dicho artículo, ofreciendo una propuesta que permite utilizar correctamente las tecnologías de la información en orden a colaborar con el objetivo de la excepción: incrementar el acceso a las obras del archivo o biblioteca beneficiaria.

PALABRAS CLAVE Derecho de autor, excepciones al derecho de autor, bibliotecas, bibliotecas virtuales, terminal de red. 


\begin{abstract}
The law 17.336 included, in its last modification, a new list of exceptions. Of special interest are those whose objective is to promote and legitimate the activities of libraries and archives. In particular, the exception contained in article $7 \mathrm{I} \mathrm{K}$ refers to the possibility of linking the activities of libraries and archives with the new information technologies, enabling the access to the works of their collections to be significantly increased. This paper seeks to construe as fully as possible the majority of the undetermined concepts of said exception, offering an interpretation that would allow the correct use of the information technologies in order to aid with the focus of the exception: Increase the access to the works of the library or archive benefited by it.
\end{abstract}

KEYWORDS Copyright, copyright exceptions, libraries, virtual libraries, network host.

\title{
INTRODUCCIÓN
}

\section{NOCIONES BÁSICAS}

Para entender de qué manera funcionan y se aplican las excepciones al derecho de autor, y, en específico, aquella que es objeto del presente artículo, es necesario dar un ligero recorrido por las instituciones jurídicas que la envuelven. De esta forma, lo primero a tener en mente es una idea de propiedad intelectual que nosotros entendemos como el marco normativo que tiene por objeto la protección de toda creación del intelecto humano, así como sus actividades conexas. ${ }^{\mathrm{T}}$

Debemos recordar que la propiedad intelectual se divide en derecho de autor, por un lado, y el derecho de propiedad industrial, por otro. De estas disciplinas nos referiremos exclusivamente a la primera, que protege las obras literarias y $\operatorname{artísticas~}^{2}$ y que entendemos como aquel cuerpo

I. Definición que sintetizamos de la que ofrece el profesor Antequera Parilli (2000: 2) y la de OMPI (20I4: 3). Walker (2OI4:4) la define como «aquella área del derecho que regula la creación, uso y explotación del trabajo [sic] que es resultado de procesos creativos o mentales», siguiendo una línea anglosajona.

2. El Convenio de Berna, en el párrafo primero de su artículo 2, señala: «Los términos 'obras literarias y artísticas' comprenden todas las producciones en el campo literario, científico y artístico, cualquiera que sea el modo o forma de expresión, tales como los 
normativo que protege, por el solo hecho de su creación, los derechos de los autores sobre sus obras literarias o artísticas. ${ }^{3}$

Pero la protección de estas obras no tendría demasiado sentido en el caso de que no existiera alguien que estuviera interesado en acceder a ellas de manera no prevista por el titular o derechamente prohibida por éste. Estas personas que interactúan con las obras podríamos llamarlas de muchas formas — comunidad, grupo, fanáticos, interesados, público-, pero tienen siempre una característica fundamental, cual es la de utilizar la obra. ${ }^{4}$

Tenemos, entonces, varios intereses que ponderar. Sirinelli (I999: I0) señala tres asuntos que tener en mente, y que son: en primer lugar, el interés de los autores en virtud del cual el creador de la obra debe poder subsistir de sus creaciones; el segundo dice relación con el mecenas o aquel que incurre en gastos para poder realizar la obra y la protección que debiera tener su inversión; y finalmente, en tercer lugar se encuentra el interés público, relativo directamente a los usuarios que buscan ac-

libros, folletos y otros escritos; las conferencias, alocuciones, sermones y otras obras de la misma naturaleza; las obras dramáticas o dramático-musicales; las obras coreográficas y las pantomimas; las composiciones musicales con o sin letra; las obras cinematográficas, a las cuales se asimilan las obras expresadas por procedimiento análogo a la cinematografía; las obras de dibujo, pintura, arquitectura, escultura, grabado, litografía; las obras fotográficas a las cuales se asimilan las expresadas por procedimiento análogo a la fotografía; las obras de artes aplicadas; las ilustraciones, mapas, planos, croquis y obras plásticas relativos a la geografía, a la topografía, a la arquitectura o a las ciencias».

3. Hay, sin embargo, quienes objetan que las categorías de «autor» o de «obras» sean precisas. Satanowsky señala, a propósito de la denominación «derecho de autor» o «derecho autoral», que «aunque los autores sean los sujetos fundamentales del derecho intelectual, también son protegidos los realizadores, intérpretes, etc.», y que la denominación de obras artísticas y literarias no abarca la totalidad de los derechos comprendidos por el derecho de autor, pues dejaría fuera los derechos conexos que son protegidos, mas no son obras (Satanowsky, I954: 57).

4. Sobre la utilización, Walker señala que «apoya la postulación planteada por Pablo Ruiz-Tagle, quien señala que el carácter no taxativo de las facultades que emanan del derecho patrimonial se deduce del artículo i9 de la Ley de Propiedad Intelectual que señala que 'nadie podrá utilizar públicamente una obra del dominio privado sin haber obtenido la autorización expresa del titular del derecho de autor'. La expresión 'utilización' sería tan amplia que no sólo abarcaría las facultades expresamente reguladas en la ley sino que todos los posibles usos que pueden ser desarrollados en relación con una obra» (Walker, 20I4: I 59). 
ceder a las obras por motivos educacionales, recreacionales y culturales entre muchos otros. Para solucionar este conflicto y ponderar los intereses de todos quienes están involucrados, el sistema de derechos de autor creó la institución de las excepciones.

\section{LAS EXCEPCIONES EN EL DERECHO DE AUTOR}

Existe cierto nivel de disenso sobre el concepto de la excepción, al punto de que se ha señalado que debería ser llamada de forma distinta. De esta forma, Burrel y Coleman (2005: Io) señalan que llamarles «excepción» sería, de alguna forma, comenzar desde el área de los autores, mientras que otras visiones más progresistas en pos del público las llamarían «derechos de usuario» o «derechos del público», considerando a este elemento equivalente al derecho de los autores o titulares. Nos decantaremos por la primera opción no por una cuestión ideológica, sino porque, como señalan los autores recién citados, engloba bien el concepto y, actualmente, la institución de las excepciones está lejos de ser equivalente al derecho que los autores y titulares tienen respecto de sus obras.

Las excepciones son básicamente una limitación a los derechos de autor y conexos respecto de los titulares sobre sus obras, por lo que pertenecen a una esfera en donde éstos no tienen la facultad de desautorizar que los usuarios beneficiarios accedan a la obra de la manera prevista por la excepción. De esta forma, y como se ha señalado, buscan equilibrar el conflicto en cuestión de forma previa, autorizando usos que tienden a ser específicos de la obra que el legislador considera necesarios y que pueden venir acompañados o no por una remuneración. ${ }^{5}$

En nuestro país, el catálogo de este tipo de limitaciones era bastante acotado hasta la última modificación de la Ley I7.336 de Propiedad Intelectual en 20I0. En dicha oportunidad se aumentó considerablemente

5. En el sitio web de la OMPI podemos encontrar una explicación de la esencia de las excepciones, que aparecen como necesarias para mantener el equilibrio entre los actores involucrados. Señala que «con el fin de mantener un equilibrio apropiado entre los intereses de los titulares del derecho y los usuarios de contenidos protegidos, las leyes sobre derecho de autor permiten ciertas limitaciones respecto de los derechos patrimoniales, es decir, en los casos en los que las obras protegidas pueden ser utilizadas sin autorización del titular de los derechos y contra el pago o no de una remuneración» (OMPI, Limitaciones y excepciones, disponible en <http://www.wipo.int/copyright/es/limitations/>). 
la lista de excepciones, naciendo interesantes opciones que trataremos más adelante. ${ }^{6}$

Sin embargo, estos catálogos no pueden incluir cualquier excepción que el legislador estime conveniente si el Estado participa en determinados organismos multilaterales y ha firmado tratados relativos al derecho de autor. En consideración a los tratados internacionales suscritos por nuestro país, ${ }^{7}$ para que la excepción propuesta esté acorde a derecho debe respetar un test que se conoce como la «regla de los tres pasos». ${ }^{8}$ Esta consiste en tres cuestiones que deben tenerse presentes:

- La excepción debe tratarse como un caso especial.

- La excepción no puede interferir con la explotación de la norma.

- La excepción no puede causar un daño injustificado al autor.

Cumplido lo anterior, la excepción es susceptible de incluirse en la ley sin que exista un incumplimiento del tratado y puede, por tanto, ser alegada por el beneficiario. Por la naturaleza de los derechos de autor de ser esencialmente reivindicables, las excepciones deben ser interpretadas en juicio y adjudicadas por el juez para gozar de completa validez práctica, puesto que los titulares siempre pueden alegar que las utilizaciones de los presuntos usuarios de la excepción son usos que escapan de lo previsto por la norma. Sin perjuicio de ello, no es menos cierto que su interpretación también es de gran utilidad para la validez de un mejor ejercicio de los derechos, pues de una u otra manera fijan parámetros de buenas prácticas respecto de las utilizaciones.

Los beneficiarios de las distintas limitaciones impuestas a los derechos de autor son diversos y abarcan a toda la comunidad interesada.

6. Para un análisis de los principales cambios que se produjeron con la reforma y en especial respecto de las excepciones, véase Álvarez Valenzuela (20I I).

7. Entre los tratados en los que participa nuestro país, la «Regla de los tres pasos» aparece normada originalmente en el Convenio de Berna. Sin perjuicio de lo anterior, hay otros instrumentos relevantes al derecho de autor en los que participa nuestro país. Estos son el Tratado sobre Aspectos de los Derechos de Propiedad Intelectual relacionados con el Comercio (ADPIC, que se aplica a todo miembro de la OMC, organización de la cual nuestro país es miembro) y el Tratado de la OMPI sobre Derecho de Autor.

8. En el Convenio de Berna la regla se aplica únicamente al derecho de reproducción, pero en los ADPIC esta situación se amplía al resto de los casos. 
Incluyen, entre otros, a privados que realizan actividades específicas, académicos, instituciones de educación, museos, archivos y lo que nos interesa en el particular, bibliotecas (Fernández-Molina, 2008: I24).

\section{EXCEPCIONES Y BIBLIOTECAS}

Las bibliotecas, al mantener largas colecciones de obras principalmente literarias, son un espacio donde convergen los intereses tanto de los autores como del público. Los segundos acceden a la red cultural que aumenta gracias a los primeros, siendo la institución bibliotecaria una intermediaria en la transacción. ${ }^{9}$

Tradicionalmente, los sistemas utilizados por éstas son el de consulta y el de préstamo: la biblioteca mantiene una colección de libros, revistas, periódicos, etcétera, que los usuarios pueden consultar en sala o llevarse a su hogar por un tiempo determinado, so pena de multa o suspensión de beneficios. Al estar las obras plasmadas en un soporte físico — por ejemplo, la tinta y el papel— no se produce ningún problema en entregar los ejemplares a los usuarios. ${ }^{\circ}$

Pero, ¿sería posible que utilizásemos la tecnología para ampliar el espectro de alcance de la biblioteca e implementar nuevos sistemas de acceso a la cultura? ${ }^{\text {I }}$

Como señaláramos previamente, la última modificación de la Ley I 7.336 añadió varias excepciones y, dentro de éstas, un grupo conside-

9. Respecto del nivel de desarrollo que deben tener las excepciones, Chapman señala que «el tipo y nivel de protección otorgados en virtud de cualquier régimen de propiedad intelectual deben facilitar y fomentar la participación cultural y el progreso científico, de modo que se beneficie ampliamente a los miembros de la sociedad tanto a nivel individual como colectivo» (20II: I6). Si consideramos que las bibliotecas aparecen como un instrumento fundamental del acercamiento de la cultura a la población, entonces el argumento cobra todavía más fuerza.

Iо. Al tener un soporte material y haber sido adquirida por la biblioteca, la obra se agota luego de la utilización del derecho de distribución del titular y éste ya no puede ejercer control alguno sobre ese ejemplar en particular. Artículo I 8 de la Ley I7.336: "Con todo, la primera venta u otra transferencia de propiedad en Chile o el extranjero, agota el derecho de distribución nacional e internacionalmente con respecto del original o ejemplar transferido». El tema tiene una profundidad académica superior y no será tratado en el artículo.

I I. Sobre el punto, véase Fernández-Molina (2008). 
rable de ellas tiene como beneficiarias a las bibliotecas además de instituciones similares, como los museos y archivos. En particular aquella hallada en el artículo 7 I K es de gran interés, puesto que menciona conceptos inéditos en nuestra legislación, como «reproducción electrónica», «terminales de redes» y «copias electrónicas» y tiene como fin la posibilidad de poner a disposición de los usuarios colecciones de la biblioteca. Desgraciadamente esta norma es compleja por los conceptos de alcance dudoso y por su mismo fin, que es discutible debido a la amplitud del uso exceptuado dependiendo de su interpretación, además de la nula jurisprudencia nacional y el escaso tratamiento en derecho comparado de excepciones similares.

\section{BREVE COMENTARIO SOBRE LA LEGISLACIÓN COMPARADA}

Si bien existen tratados sobre derecho de autor que regulan la materia para muchos países, la regulación pormenorizada depende de cada Estado y la fundamentación de ella - y por tanto de sus excepcionesdependen en gran medida de sus características históricas, políticas y sociales (Crews, 2008: I7). ${ }^{22}$ Pero aun así, las excepciones sobre temas parecidos tienden a ser similares en las distintas legislaciones, puesto que, en relación con las bibliotecas, generalmente tratan de uno de estos cuatro tópicos: copia o reproducción por parte de la biblioteca, excepciones para los fines de investigación y estudio, excepciones para fines de preservación y sustitución, y, finalmente, excepciones relativas a préstamos interbibliotecarios (Crews, 2008; véase partes VI, VII, VIII y IX).

Sin perjuicio de lo anterior, pasaremos revista a países en condiciones relativamente similares al nuestro y que tienen legislaciones con excepciones parecidas a nuestro artículo 7 I K: Brasil y España. ${ }^{\text {I3 }}$

I2. Es de relevancia mencionar que durante el año 2014 el profesor Crews amplió su estudio respecto de las bibliotecas, actualizando la información sobre países que entre el año 2008 y el 20I 4 habían modificado su catálogo de excepciones y añadiendo nuevas naciones. Sin perjuicio de ello y fuera de la inclusión de las nuevas excepciones de nuestro país, la referencia seguirá siendo el texto base de 2008 , pues en él se incluye el estudio completo (que incluye doctrina) y no sólo las tablas de excepciones por país.

I3. Al análisis de la legislación comparada respecto del tema de excepciones de bibliotecas dedicamos un capítulo entero de nuestra memoria de grado, que expande todos los tópicos aquí tratados y sobre todo éste. Se trata del capítulo 3, "Catálogo y breve 
La ley de la República Federal del Brasil data de I998 y desde entonces no ha sido modificada en lo referido a nuestra materia, según lo señalado en sitio de la OMPI. Si bien Crews (2008: I42) señala que no existen normas relativas a bibliotecas, se tramita un proyecto de revisión a la Ley 9.6 Io/98 en el que existiría una norma similar a nuestro artículo 7 I K.

La norma en cuestión previene que no se incurrirá en ofensa para los derechos de los autores, sin requerir autorización ni remuneración de por medio, la comunicación pública y la puesta a disposición de obras protegidas que integren las colecciones de los fondos bibliotecarios y de otras instituciones culturales, siempre que tengan fines de búsqueda, investigación o estudio, por cualquier medio o proceso en el interior de sus instalaciones o por medio de sus redes informáticas cerradas. ${ }^{\mathrm{I}}{ }^{\mathrm{T}}$

El precepto permitiría la comunicación pública incluso en su modo de puesta a disposición de obras protegidas pertenecientes a las colecciones de la biblioteca, siempre que se cumplan determinados fines que comparten entre sí el carácter cultural y toda vez que éstas se realicen en el lugar físico de la biblioteca o por medio de redes cerradas de la misma. Curiosamente no menciona nada sobre si los fines al utilizar la excepción pueden o no conllevar el interés comercial o lucrativo, sino que meramente los liga al estudio y la investigación.

Esta excepción permitiría, por ejemplo, la comunicación pública de una película que esté en su colección en alguna sala de la biblioteca y, al mismo tiempo, subir la función a la red cerrada para ser revisada en el instante o más tarde por los usuarios de la biblioteca.

Cabe señalar especialmente el hecho de que delimite el espacio en donde puede efectuarse la puesta a disposición, señalando que específi-

análisis de las excepciones y limitaciones relativas a bibliotecas en los ordenamientos comparados de derecho de autor» (Castro y Grubsic, 20I4).

I4. «A comunicação e a colocação à disposição do público de obras intelectuais protegidas que integrem as coleções ou acervos de bibliotecas, arquivos, centros de documentação, museus, cinematecas e demais instituições museológicas, para fins de pesquisa, investigação ou estudo, por qualquer meio ou processo, no interior de suas instalações ou por meio de suas redes fechadas de informática». (Republica Federal de Brasil, Projeto de Lei 9.6Io, Altera, atualiza e consolida a legislação sobre direitos autorais e dá outras providências: artículo 46, XVI). 
camente esto debe realizarse dentro de la biblioteca. Volveremos sobre el punto al momento de realizar el análisis de nuestro artículo 7 I K.

\section{ESPAÑA}

En España existe una norma que trata específicamente el tema de las excepciones respecto de bibliotecas. Dicha norma es el artículo 37 de la Ley de Propiedad Intelectual, que se divide en tres puntos, de los cuales sólo nos interesa el tercero. Este punto establece una excepción libre y remunerada sobre la comunicación pública y puesta a disposición de obras a través de una red cerrada e interna, siempre que las obras sean parte de las colecciones del establecimiento, se accedan con fines de investigación y no tengan condición de adquisición o licencia. ${ }^{\mathrm{I}}$

Pareciera que, al hablar de redes, esta excepción implicaría la utilización de aparatos electrónicos, pero no se hace alusión directa a ninguno. En cualquier caso, de llegar a interpretarse de otro modo no tendría sentido lógico y caería en un absurdo, por lo que debemos inclinarnos por considerar que incluye dicha tecnología y, de este modo, se asemeja en algunos puntos a nuestra norma.

Sin perjuicio de lo anterior, en esta excepción se pueden contrastar algunas cuestiones respecto de la nuestra. En primer lugar, circunscribe la realización de la puesta a disposición en terminales especializados instalados para dicho efecto en el local de la biblioteca. ${ }^{16}$ Como veremos luego, la delimitación de ámbito especial en el cual se debe ejercer la excepción puede cambiar completamente su impacto y en esta norma, como en la de Brasil, se circunscribe al ámbito del local bibliotecario.

I 5. «3. No necesitará autorización del autor la comunicación de obras o su puesta a disposición de personas concretas del público a efectos de investigación cuando se realice mediante red cerrada e interna a través de terminales especializados instalados a tal efecto en los locales de los establecimientos citados en el anterior apartado y siempre que tales obras figuren en las colecciones del propio establecimiento y no sean objeto de condiciones de adquisición o de licencia. Todo ello sin perjuicio del derecho del autor a percibir una remuneración equitativa».

I6. El punto anterior del mismo artículo señala: «Asimismo, los museos, archivos, bibliotecas, hemerotecas, fonotecas o filmotecas de titularidad pública o que pertenezcan a entidades de interés general de carácter cultural, científico o educativo sin ánimo de lucro, o a instituciones docentes integradas en el sistema educativo español». 
En segundo lugar, la excepción española estipula directamente el deber de remuneración para con el titular del derecho, cuestión que se aleja de todas las excepciones relativas a bibliotecas de nuestro país.

En resumidas cuentas, las excepciones similares en otros países no se condicen exactamente con la que se estipula en nuestro artículo 7 I K, por lo que nos sirven únicamente para definir sus límites en la diferencia de ellas.

\section{ANÁLISIS DEL ARTÍ́CULO $71 \mathrm{~K}$}

\section{DERECHO EXCEPTUADO}

El artículo 7 $\mathrm{I} \mathrm{K}^{17}$ menciona dos derechos exceptuados. Por una parte, la voz «reproducción electrónica» implica el derecho de reproducción con la circunstancia de que éste sea de forma electrónica. Por la otra, el permitir la consulta gratuita de las obras reproducidas de esta forma debe entenderse como una excepción al derecho de comunicación al público y, en particular, de la puesta a disposición.

La reproducción es, básicamente, la fijación de la obra en un medio que permita su comunicación, utilizando cualquier método o procedimiento. ${ }^{18} \mathrm{La}$ reproducción electrónica es, por tanto, aquella cuyo resultado es la fijación de la obra en un soporte electrónico. Es posible sostener, además, que cuando la norma habla de «reproducción electrónica» utiliza un término tecnológicamente neutro, es decir, no obliga al intérprete a entender que deba existir una forma particular de llevar a cabo la acción reproductora.

Además, la reproducción de la que habla la excepción tiene un fin determinado. El artículo 7 I K establece que esta reproducción electrónica

I7. Artículo 7 I K: «Las bibliotecas y archivos que no tengan fines lucrativos podrán, sin que se requiera autorización del autor o titular, ni pago de remuneración alguna, efectuar la reproducción electrónica de obras de su colección para ser consultadas gratuita y simultáneamente hasta por un número razonable de usuarios, sólo en terminales de redes de la respectiva institución y en condiciones que garanticen que no se puedan hacer copias electrónicas de esas reproducciones».

I 8. Artículo 5: «Para los efectos de esta ley, se entenderá por: [...] u) Reproducción: la fijación permanente o temporal de la obra en un medio que permita su comunicación o la obtención de copias de toda o parte de ella, por cualquier medio o procedimiento». 
sólo se podrá hacer con el fin de que las obras sean «consultadas de forma gratuita y simultáneamente por un número razonable de usuarios». De esta forma, la norma relaciona condicionalmente la reproducción electrónica con la comunicación al público. Por lo mismo, la biblioteca beneficiaria no tiene la facultad de utilizar estas reproducciones de otra forma que no sea la señalada en la excepción.

Como señala el profesor Schuster en una interpretación con la que concordamos plenamente: «Lo que tengo absolutamente claro es que la colección digital del artículo 7 I K no es la del 7 J. En el 7 I K se permite hacer una copia de mi colección analógica en forma electrónica. Pero eso no significa que una vez que yo hago esta colección me convierta en dueño de versión digital, con todo lo que ello implica» (en Castro y Grubsic, 20I2: IO, anexo I). En otras palabras, la reproducción electrónica de la que habla esta excepción no implica que las obras entren a la colección de la biblioteca en ningún caso, ni que la beneficiaria tenga un derecho de dominio sobre estas obras, pues únicamente puede administrar las reproducciones electrónicas de la manera en que la ley lo permite.

Por otro lado, la comunicación al público (o «comunicación pública» según el término legal) ${ }^{\text {I9 }}$ se refiere al hecho por el cual un grupo de personas — reunidas o no en el mismo lugar - tienen acceso a una obra, cualquiera sea el medio o procedimiento que usen al efecto y siempre que no haya una distribución previa. Parte de este derecho también contempla la puesta a disposición de la obra al público, de modo tal que sean los usuarios los que determinen el momento y lugar en el cual van a acceder a la obra.

En el contexto de la excepción en análisis, creemos que la voz «ser consultadas» es clave para entender que la comunicación al público de las obras reproducidas electrónicamente toma la modalidad de puesta a disposición, pues dicho concepto supone que es el usuario el que tiene la intención de acceder a la obra en el momento en que lo desea y está disponible, cuestión natural a toda consulta bibliotecaria. En este sentido, si analizamos el texto de la excepción veremos que no se hace mención expresa a si debe haber un lugar o momento específico para el acceso a las obras previamente reproducidas electrónicamente.

I9. Véase el artículo 5 letra v) de la Ley I7.336. 
Si bien lo anterior refuerza la interpretación de que la comunicación al público es uno de los derechos exceptuados, es relevante por otra razón. Consideramos que, si bien una interpretación a priori de la frase «terminales de redes de la propia institución» da a entender que se trata de terminales de red físicos que se encuentren dentro del recinto de la biblioteca, el concepto de terminal de red es equívoco, como intentaremos probar más adelante, abriendo la posibilidad de una puesta a disposición remota, por ejemplo, a través de Internet.

\section{SUJETO}

Las bibliotecas tienen en nuestro país un tratamiento poco específico, por lo que no es de extrañar el hecho de que no exista una definición legal al respecto. En este sentido, para simplificar su comprensión y a su vez clarificarla, tendremos en consideración dos elementos: la definición de la RAE de biblioteca en sus múltiples acepciones ${ }^{2 \circ}$ y algunos elementos mencionados en el decreto que crea a la Dirección de Bibliotecas, Archivos y Museos (Dibam). ${ }^{21}$

De esta forma, podemos presumiblemente entender que el concepto de biblioteca al que se refiere la norma como beneficiaria debe entenderse en su sentido natural y obvio, pero además teniendo presente las características que la norma citada le atribuye a toda biblioteca, cuales son las de coleccionar, ordenar, facilitar la investigación y divulgar la cultura.

Sobre los archivos no nos referiremos, aunque la mayoría de las cuestiones señaladas en el presente artículo puedan ser aplicables a su ámbito.

20. Biblioteca: «I. f. Institución cuya finalidad consiste en la adquisición, conservación, estudio y exposición de libros y documentos. 2. f. Local donde se tiene considerable número de libros ordenados para la lectura. 3. f. Mueble, estantería, etc., donde se colocan libros. 4. f. Conjunto de estos libros. 5. f. Obra en que se da cuenta de los escritores de una nación o de un ramo del saber y de las obras que han escrito».

2I. "I. Que las bibliotecas, los archivos y los museos tienen funciones semejantes y finalidades comunes, ya que coleccionan, ordenan y dan a conocer los elementos destinados a la investigación y a la divulgación de la cultura» (artículo I). 
La ley no especifica ni en este artículo, ni tampoco en los relacionados a él, qué tipo de biblioteca es la que puede beneficiarse de la excepción, salvo que ésta no tenga fines lucrativos. Esto implica que legítimamente podamos pensar en muchos tipos de bibliotecas que puedan utilizar la excepción cumpliendo el requisito de no tener los fines previamente señalados.

En este sentido, podríamos hablar por ejemplo y sólo por nombrar de categorías como las siguientes:

- Bibliotecas tradicionales o virtuales.

- Bibliotecas privadas o públicas.

- Bibliotecas especializadas o no especializadas.

Todas éstas pueden cumplir fielmente con el requisito que impone la norma y, por lo tanto, aprovechar ésta y todas las excepciones relacionadas a bibliotecas que la ley impone.

\section{EFECTO}

Permite al sujeto beneficiario efectuar la reproducción electrónica para la puesta a disposición de obras de su colección para ser consultadas gratuita y simultáneamente por un número razonable de sus usuarios en terminales de red de la institución, sin que se requiera la autorización del titular ni pago de remuneración alguna. Además, deben garantizarse las condiciones para que no se puedan hacer copias electrónicas de las reproducciones previamente realizadas.

Como se puede apreciar en la definición que hace la ley de esta excepción, existen varios conceptos indeterminados cuya interpretación correcta es vital para determinar la extensión de la restricción al derecho del titular y la extensión de lo autorizado. Estos elementos serán analizados en detalle a continuación.

\section{CONDICIONES}

En primer lugar, la excepción señala que no será necesaria la autorización del autor o titular ni pagarle remuneración alguna. Así, se inscribe 
esta excepción en aquellas denominadas libres y gratuitas, en tanto no sólo es permitida la conducta sin autorización del titular de los derechos, sino que adicionalmente la ley señala, de forma expresa, que no se le deberá pagar remuneración alguna.

\section{Número de usuarios}

Luego, la norma califica el número de usuarios que podrán acceder de forma simultánea con la palabra «razonable». Este concepto es particularmente importante, en tanto representa de forma patente la necesidad de equilibrar con un criterio justo o suficiente los intereses de ambos extremos del continuo que es el derecho de autor: los usuarios y los titulares de derechos; el acceso y la protección de las obras protegidas.

El diccionario de la Real Academia Española, al definir «razonable», señala que se trata de algo «arreglado, justo, conforme a razón» o algo «mediano, regular, bastante en calidad o en cantidad». Esta última voz parece ser la más adecuada pues delimita el ámbito del concepto y lo une a la satisfacción de cierto estándar, que puede ser cualitativo o cuantitativo.

La pregunta que cabe hacerse ahora es: ¿qué es bastante y en base a qué criterios se determina? Consideramos que aquí entran en juego dos consideraciones. La primera, se refiere al derecho de acceso a la cultura de los usuarios, mientras que la segunda dice relación con la función misma que cumple la biblioteca en su entorno inmediato, sobre todo en cuanto a su alcance, ya sea nos refiramos al total de individuos que utiliza la biblioteca o a la cantidad de personas a la cual espera alcanzar.

Si utilizamos solamente el acceso a la cultura como criterio para interpretar qué es razonable y así definir cualitativa y/o cuantitativamente el estándar a utilizar para considerar algo como razonable, posiblemente lleguemos a la conclusión de que el número de usuarios es el máximo posible. En este caso, el criterio cuantitativo se relaciona de manera directa con el cualitativo: mientras más, mejor.

Dicho de otra manera, resulta difícil encontrar en la noción misma de acceso a la cultura límites «intrínsecos», en tanto tiende a ser lo más amplia posible y abarcar la mayor cantidad de personas. Es por esto que las limitaciones se presentan de manera «extrínseca», entrando en esta categoría los derechos de los titulares o la protección de las obras, 
por ejemplo. Es en este aspecto que el plano de la función concreta de la biblioteca se nos hace útil.

Así, las circunstancias de cada biblioteca beneficiaria determinarán de manera concreta de qué forma se limita el acceso a la cultura —que busca en principio ser lo más extenso posible- de acuerdo a las necesidades reales de la biblioteca y con el fin de no vulnerar derechos de los terceros titulares.

En este sentido, no parece razonable utilizar el mismo criterio para una biblioteca comunal que para la Biblioteca Nacional, pues en ambos casos la noción de "número razonable de usuarios» cambiará radicalmente debido a la cobertura que cada una de las bibliotecas posee en la práctica.

De la misma forma, no se justificaría que la biblioteca de una universidad privada otorgara acceso a un número de usuarios superior a su matrícula o que la biblioteca de una fundación, que sea privada, entregue al público general su colección en consulta sujeta a la excepción, porque estima que un número razonable de usuarios es el mayor posible.

La fórmula está en considerar adecuadamente las necesidades, el tamaño y la difusión social del conocimiento de una biblioteca dada e integrar estos criterios al examen de razonabilidad. De más está decir, para finalizar esta parte, que el acceso general a las obras no está permitido. Como señala el profesor Schuster, "cuando yo digo 'un número razonable de usuarios' la discusión que se podría haber producido es que si las bibliotecas podían poner sus colecciones a disposición del público en general. Eso está restringido, está claramente restringido. Tiene que ser en su red, para los usuarios de la biblioteca» (en Castro y Grubsic, 20I4: 7, anexo I).

El tercer y último elemento que debe ser considerado para efectos del examen de razonabilidad es si la extensión que se le da al concepto de acuerdo a los dos criterios anteriores puede ser o no una violación a la regla de los tres pasos del derecho de autor. ${ }^{22}$ Dado que la regla de

22. Como ya hemos mencionado, esta regla, establecida en el artículo 9.2 del Convenio de Berna, considera tres criterios que se extraen del propio artículo, y que la excepción debe cumplir para ser legítima: que se refiera a casos especiales, que no atente contra la explotación normal de la obra y que no cause un perjuicio injustificado a los intereses legítimos del autor. 
los tres pasos en Chile sólo es vinculante para el legislador, ${ }^{23}$ debemos suponer que la redacción de las excepciones la satisface, pues la prueba de su implementación se tuvo que hacer antes de la redacción legislativa de la norma.

En relación a lo anterior y como un elemento que colabora con la adecuada interpretación de la excepción, consideramos que un número demasiado grande de usuarios podría comprometer el hecho de que se trate de un caso especial y/o posibilitaría que se cause perjuicio al titular de los derechos. Sin embargo, creemos que los criterios anteriores permiten balancear de manera adecuada estos intereses, controlando de forma medianamente objetiva y favorable la interpretación de la excepción.

Sin embargo, estimamos que una potencial forma expresa de dañar de manera efectiva los derechos de los titulares involucrados radica en la inobservancia de las condiciones que se estudiarán a continuación, a saber: el problema del terminal de red y la necesidad de evitar la reproducción de las obras digitalizadas.

\section{Redes}

Para comprender completamente el contenido del artículo 7 I K, es necesario hacer precisiones técnicas. Esto se debe a que la condición que impone la norma consiste en que las consultas de los usuarios necesariamente tienen que ser realizadas en terminales de redes de la respectiva institución, por lo que se hace imprescindible definir «red» $\mathrm{y}$ «terminal de red», para entender a qué se está refiriendo.

De acuerdo al profesor Jens Hardings, «una red es básicamente una infraestructura que permite transmitir datos a través de un medio» (Castro y Grubsic, 20I4: 8, anexo 2). Existen varios modelos de análisis,

23. Tradicionalmente, su utilización se ha considerado vinculante sólo para los Estados obligados por los tratados. Sin embargo, se ha traspuesto e incorporado a diversas legislaciones, lo que redunda en la aplicación de la regla de los tres pasos como un criterio ex post, capaz de ser utilizada por los jueces no sólo para resolver casos difíciles, sino como una forma particular de extender el ámbito de las excepciones existentes, siempre y cuando se cumpla con los requisitos que exige (Griffiths, 2009). En Chile, previo a la reforma de 2010 de la Ley I7.336, existía una norma que extendía su uso a nivel jurisprudencial. Dicha disposición fue eliminada en la reforma referida (Álvarez Valenzuela, 20I I). 
aunque son dos los más relevantes: por una parte está el modelo ISO/ $\mathrm{OSI}^{24} \mathrm{y}$, por otra, el TCP/IP, ${ }^{25}$ los cuales explican mediante capas las diversas funciones de una red. Para efectos de este trabajo, cuando hablemos de red nos referiremos en particular al modelo TCP/IP, pues es el más simple y el más utilizado actualmente. De acuerdo a Tanenbaum (20I I: 46), posee cuatro capas, algunas relacionadas con el modelo OSI y otras que son propias del modelo TCP/IP. Si bien no es el objeto de este trabajo abordarlas en profundidad, las cuatro capas son: capa de enlace, capa de Internet, capa de transporte y capa de aplicación.

Si queremos comprender el modo en que se construyen las redes, es de suma importancia entender a cabalidad el concepto de host-to-network. En palabras del profesor Hardings:

Cuando nosotros tenemos una red de datos, digamos, lo que hay es básicamente una parte física, y una forma de conexión de esa parte física, porque no me sirve tener un cable si no sé cómo mandar un bit de un punto a otro, hay una señal eléctrica que de alguna forma yo la puedo generar en un lado y leer al otro. Entonces esas dos cosas juntas forman esto que se llama el host-to-network (Castro y Grubsic, 20I4: 2, anexo 2).

En otras palabras, el host-to-network, también conocido como «capa de enlace» en el modelo TCP/IP, ${ }^{26}$ es aquél que se encarga de asegurar las conexiones físicas entre los equipos miembros de la red (por ejemplo, mediante cables de fibra óptica) que permiten que un bit sea efectiva-

24. El modelo ISO/OSI (siglas para Interconexión de Sistemas Abiertos, u Open Systems Interconnection) es un estándar internacional para la interconexión creado por la Organización de Estándares Internacional (ISO, por su nombre en inglés) cuyo objetivo era crear una base común que permita la comunicación entre sistemas informáticos, describiendo los sistemas de redes mediante capas abstractas a las cuales está asignada una función, cuyo éxito determina el éxito de la capa que sigue (International Organization for Standardization, I996).

25. El modelo TCP/IP es una versión simplificada del modelo OSI, que condensa varias de las capas en un modelo más funcional y comprimido. Es el protocolo de interconexión de red usado en Internet, lo que lo convierte en el más utilizado en la actualidad.

26. En el modelo ISO/OSI esto correspondería tanto a la capa física como a la capa de enlace de datos. Estas capas no son tratadas de manera separada en el modelo TCP/IP, y hay algunos autores que no consideran que la «capa de enlace» de dicho modelo sea propiamente una capa, sino que más bien una interface (Tanenbaum, 20II: 54). 
mente transmitido de un equipo a otro, de manera física (no abstracta), y además de gestionar los vínculos entre dichos equipos en forma de redes. Resumiendo, es la forma en que un equipo se conecta a una red.

El segundo concepto crucial es el que se refiere a la capa de transporte. En esencia, la función de la capa de transporte es tomar los datos, dividirlos si es que fuera necesario, pasarlos a la capa de enlace, asegurándose de que en el otro extremo del canal de comunicación los datos aparezcan íntegros. El profesor Hardings señala que «es la [capa] que de alguna forma trata de garantizar de que el orden de los paquetes sea el correcto, y que al final toda la información llegue. Que no llegue repetida ni falte información, que llegue en el orden correcto» (Castro y Grubsic, 2014: 3, anexo 2).

Es decir, no se trata de una conexión host-to-network, sino de una conexión que se realiza sobre una red, entre dos equipos que están en redes diferentes, por lo que se trata de una conexión host-to-host.

La capa de transporte representa un punto de inflexión. Tanto en el modelo TCP/IP y en el ISO/OSI las capas que preceden el establecimiento de la capa de transporte y le sirven de soporte se ocupan de conectar cada máquina con su vecino inmediato, físicamente, mientras que la capa de transporte genera un vínculo entre el lugar donde se emitió el bit y hasta el último receptor del mismo (Tanenbaum, 20I 2: 44).

Esto implica que las capas anteriores conectan todos los puntos intermedios por donde debe pasar la información, mientras que la capa de transporte conecta los extremos. La capa de transporte se convierte entonces en el equivalente lógico de un cable, no importando la forma en la que se transmite la información, sino el hecho de que se pueda introducir una señal por uno de sus extremos y se pueda recibir de manera confiable en el otro. Este principio o regla de confiabilidad es la característica esencial de la conexión host-to-host.

\section{Terminales de red}

Ahora bien, ¿cómo se extrae el concepto de terminal de red a partir del concepto de red que acabamos de dar? Un terminal de red es «un dispositivo que se conecta a una de estas redes, y permite interactuar con otros dispositivos» (Castro y Grubsic, 20 I4: 8, anexo 2). Vendría a ser equivalente al concepto de host que hemos estado usando. 
En principio, estos dispositivos o hosts sólo podrían ser terminales físicos. A priori, un terminal es algo que se conecta con una red y dado que la forma de acceder a las redes es mediante un vínculo, explicado como un enlace físico, la opinión parece tener cierto sustento.

Sin embargo, el hecho de que la capa de transporte sea considerada lógicamente como un cable en el que se cumple la regla de la confiabilidad — que quiere decir que un bit entra por un extremo y sale por el otro- permite elaborar redes sobre redes. Dicho de otra forma, siempre que una red se pueda utilizar como cable, se puede construir una red sobre ella, superponiendo una red a la otra. El profesor Hardings explica esta superposición con el siguiente ejemplo:

¿Ustedes alcanzaron a usar un módem alguna vez? Que es un supuesto: yo tengo una red telefónica, que es una forma de transmitir voz, y lo que yo hago es que sobre eso quiero transmitir datos. Entonces yo tomo esa red, que es bastante compleja, de telefonía, y yo transformo los datos en sonidos, lo transmito a través de eso y después los vuelvo a transformar en datos. Yo uso la telefonía, que de por sí es una red, pero lo uso como si fuera mi cable físico. Lo que yo meto por acá, sale por allá. Con ciertas diferencias, que yo soy capaz de controlar. A partir de eso yo puedo construir una especie de red, que en vez de usar un cable físico, usa la telefonía. El mismo concepto aplica en las redes de datos, donde yo la red de datos la puedo usar como si fuera una interconexión (en Castro y Grubsic, 20I4: 8, anexo 2).

En otras palabras, se puede utilizar cualquier red existente como un «cable» o, en términos más técnicos, cualquier red existente como la capa de transporte de otra red construida sobre ella, siempre que se cumpla con la regla de confiabilidad.

El modelo $\mathrm{VPN}^{27}$ es justamente una aplicación de este principio. ${ }^{28}$ Si consideramos Internet como nuestra capa de transporte, podemos construir una red que la utilice como «cable» y de esta forma se puede establecer una red cerrada y local, usando en lugar de cables de red, el equivalente lógico que proporciona la web.

27. Red Privada Virtual, VPN por su nombre en inglés.

28. Olifer (2007) la define como «una red (o servicio) que reproduce (emula) la propiedades de una red privada real utilizando la infraestructura de redes públicas». La traducción es nuestra. 
Para completar este tipo de redes, se les agrega un sistema de cifrado que aumenta su seguridad, cuyo trabajo es impedir que los puntos intermedios por donde pase la información puedan descifrarla para saber de qué se trata o, menos aún, modificarla. Éste es el aspecto que permite utilizar la infraestructura de redes públicas para montar una red privada.

Ahora bien, es claro que los dispositivos que acceden a esa red VPN son terminales de esa red y que son, en rigor, terminales físicos. Siguiendo esta línea, la ley no hace ninguna distinción especial al nombrar a los terminales en el artículo. Sin embargo, los terminales de red no son ni conceptualmente ni en la práctica necesariamente físicos y, por tanto, cabe legítimamente cuestionarse si los terminales de red virtuales están contemplados dentro del concepto de «terminal de red» que emplea el artículo 7 I K. Para entender esto, es preciso conocer el concepto de máquina virtual.

\section{Máquina virtual}

Cuando uno habla de máquina virtual se está refiriendo a lo que técnicamente se conoce como la implementación de una capa de software dentro de una máquina real, para virtualizar sobre ella otra máquina (la virtual) que es capaz de funcionar como una instancia separada de su contraparte física, pero utilizando los mismos recursos que ésta. En este sentido:

Múltiples máquinas virtuales pueden ser implementadas en una misma plataforma de hardware para proveer a individuos o a grupos de usuarios con sus propios entornos de sistema. Estos entornos de sistema distintos (posiblemente con sistemas operativos distintos) también proveen aislamiento y seguridad mejorada. Un gran servidor con muchos procesadores puede ser dividido en servidores más pequeños, al mismo tiempo que retiene la capacidad de balancear el uso de los recursos de hardware a través del sistema (Smith y Nair, 2005: 4. La traducción es nuestra).

Al ser posible crear máquinas virtuales, es también posible conectarlas a una red como terminales o hosts. Aquí la diferencia entre máquinas reales y virtuales se difumina, porque un host virtual puede solicitar información a un servidor, sin que este último pueda discernir si se trata de un dispositivo real o no. Sobre el particular señala Hardings: 
Es perfectamente posible pensar un terminal virtual ı००\%. Que nunca despliegue nada, y que exista solamente como algo virtual. O sea, no se necesita un despliegue físico en ninguna parte. $\mathrm{Y}$ de hecho ni siquiera el computador tiene que ser real, puede ser virtual también y estar en otro computador [...] un computador que está conectado a la red en otra parte, no tiene cómo diferenciar si es el computador real o una máquina virtual dentro de un computador la que está haciendo la solicitud (Castro y Grubsic, 2014: 9, anexo 2).

De lo anterior se extrae que la virtualización puede alcanzar distintas magnitudes: puede ser un subsistema particular (como un disco duro) o puede ser incluso un sistema computacional completo dentro de otro.

Del modo anterior, un terminal virtual de red sería un software que virtualiza todos los aspectos necesarios de un sistema para convertirse en un terminal de red, actuando como un dispositivo emisor/receptor de la información. ${ }^{29}$ Este dispositivo es el final del «cable» que mencionamos al hablar de la capa de transporte.

Desde el punto de vista técnico entonces, es viable referirse como «terminal de red» tanto a un equipo físico como a un dispositivo virtual, siempre que ambos hagan las veces de host o terminal en una red. Lo anterior abre un abanico de posibilidades en los que el terminal de red que accede a la red de la biblioteca donde están digitalizadas las obras no se encuentre físicamente en el recinto de la biblioteca, si no que se traten de terminales virtualizados que, técnicamente a lo menos, pueden estar en cualquier lugar.

\section{Terminales de red propios de la institución}

Con todo, lo anterior no cumple cabalmente con el requisito que exige la ley. Esto porque pone como condición adicional que se trate de terminales de red que sean de la propia institución, lo que ha dado pie para una interpretación que señala que los terminales deben encontrarse dentro del recinto de la biblioteca, no pudiendo encontrarse fuera de ellas,

\footnotetext{
29. Este terminal virtual puede ser un software en sí mismo, autónomo, o una máquina virtual completa que virtualice un computador completo. En términos prácticos, mientras ambos puedan ser un host, para la red con la que se comunican no son lógicamente diferentes, y son equivalentes a un terminal físico.
} 
como sería en el hogar de los usuarios, por ejemplo, cuestión que sería posible si utilizamos terminales virtuales. Entonces, ¿podemos entender que esta exigencia legal limita el concepto de terminal de red sólo a los terminales físicos? Para aclarar este punto resulta adecuado revisar la historia de la Ley 20.435 , que modifica la Ley I7.336, incluyendo estas excepciones.

La redacción original del artículo 7 I K señalaba al respecto que la consulta de las obras por parte de los usuarios podría ser realizada «sólo en terminales de uso local de la respectiva institución» (Biblioteca del Congreso Nacional, 20ıо: IоI). Esta redacción no prosperó, pues a pesar de los intentos del gobierno de entonces, la discusión legislativa decidió eliminar esta referencia. ${ }^{30}$

A mayor abundamiento, se reconoce expresamente que la eliminación de los vocablos «de uso local» no sólo se explica por contravenir el espíritu original de la excepción que implicaba un elemento explícito de territorialidad, sino que expresamente se señaló en la discusión que la intención de eliminar dicha frase era justamente para evitar que la excepción limitara la localidad de la biblioteca. ${ }^{3 \mathrm{I}}$

En este mismo sentido, debemos tener presente que cuando el legislador quiso circunscribir una excepción a un espacio determinado lo hizo expresamente, como se puede apreciar en el caso de la excepción del artículo 7 I N.

La conclusión que podemos extraer de la forma en que se dio la discusión en el Congreso y del resultado final de ella, es que la voz «de la respectiva institución» no hace mención al espacio físico mismo de la biblioteca, sino que debe referirse a un sentido de pertenencia que difiere

30. Así, el senador Fernando Flores señaló en su momento que «no es apropiado hablar de terminales de uso local, ya que en la actualidad sólo existen computadores que se conectan a redes que permiten a los usuarios conectarse desde cualquier punto del planeta. En este mismo orden de ideas, sostuvo que esta excepción no puede limitarse a la ubicación geográfica en que se encuentra el terminal de una biblioteca que pone a disposición del público una obra en formato digital» (Biblioteca del Congreso Nacional, 2010: IO2).

3 I. Mención merece la intervención del senador Vásquez, quien «manifestó su apoyo a la propuesta de eliminar la frase 'de uso local' y opinó que no corresponde limitar esta excepción al espacio territorial en que se ubica una biblioteca» (Biblioteca del Congreso Nacional, 2010: 104-106). 
del territorial. Proponemos que la frase «de la respectiva institución» se interprete de tal modo que constituya, más que una designación territorial, una vinculación de control de la biblioteca para con el terminal de red, sea este virtual o no. De esta manera, sería la beneficiaria la que tendría que mantener un control total sobre el terminal de red, fuere cual fuere su naturaleza. Si la biblioteca contiene dentro de su recinto el terminal de red y lo opera, presumiblemente éste se encontraría bajo su control y administración. Pero, ¿puede decirse lo mismo de los terminales virtuales o remotos?

\section{Imposibilidad de hacer copias electrónicas}

Es aquí donde la dimensión de control se entreteje con la última condición que impone la ley, referida a que no se puedan realizar copias electrónicas.

De acuerdo al profesor Hardings, es mucho más sencillo mantener la seguridad y el control en un terminal virtual por medio de una máquina virtual, pues es mucho más sencillo establecer parámetros de control arbitrarios mediante el mismo código del software:

En caso del terminal virtual, yo incluso puedo ser más exigente y decir [...] aquí la biblioteca es la que puede controlar el acceso que se hace, y nunca entrego el documento original, sino que una interpretación de la página número 20, por ejemplo, del libro, y después puedo poner alguna forma de navegación, siempre controlado por la biblioteca. Incluso yo podría poner restricciones, por ejemplo, que no pueden ver más de 5 páginas por minuto, puedo poner una serie de restricciones arbitrarias que por el lado tecnológico es muy fácil de hacer. Entonces ese control es muy completo, el que se puede hacer ahí (Castro y Grubsic, 20I4, anexo 2).

El terminal virtual de red, entonces, puede estar bajo el control de la biblioteca sin necesariamente ubicarse en su recinto físico, de manera aún más efectiva que los terminales de red convencionales. Esto por cuanto se podría establecer un mecanismo de protección en el mismo código del terminal virtual de red, que limite el acceso a las obras de la manera que la biblioteca, que en el caso será su controlador, estime conveniente. 
De esta manera se puede cumplir el último requisito de la excepción, cual es que no se puedan realizar copias digitales de las obras visualizadas que fueron previamente reproducidas electrónicamente.

\section{Aplicación en bibliotecas virtuales}

Naturalmente, esto también puede aplicar a las bibliotecas virtuales. Sin embargo, el conflicto que se produce tiene que ver con el concepto de reproducción electrónica.

Dado que establecimos que lo importante era el resultado electrónico de la reproducción señalada por la excepción, es posible hacer una analogía y permitir a la biblioteca virtual reproducir su colección electrónica original, siempre que cumpla con todas las limitaciones que ya hemos explicado, como cualquier biblioteca que pretenda ser beneficiaria de la excepción del artículo 7 I K debería hacer.

\section{CONCLUSIONES}

El ámbito de las excepciones introducidas en el nuevo articulado de la Ley 17.336 es un espacio todavía medianamente desconocido para la práctica y la doctrina en nuestro país, a pesar de que han pasado algunos años desde las modificaciones de ley.

Es por ello que cada excepción, cada norma y cada supuesto son un mundo completamente fértil para las discusiones académicas de todo tipo y nivel. Aprovechando esta oportunidad, es que deseamos intentar esclarecer de la mejor manera posible el caso particular del artículo 7 I K.

Sobre esto, el hecho es que la visualización de las obras reproducidas electrónicamente por la biblioteca no necesariamente está vinculada al recinto territorial de la biblioteca, pues el terminal de red mencionado en la norma no discierne entre virtual y físico, y por tanto no debería haber problema alguno al señalar que pueda ser accedido remotamente. Este era el punto más conflictivo de todos, pues la interpretación que cada sujeto le otorgue al concepto de pertenencia entre el terminal de red en donde se visualiza la obra reproducida electrónicamente y la biblioteca, puede efectivamente mover el espacio físico en donde el usuario puede utilizar la obra. El hecho de que pueda hacerse remotamente genera un efecto mucho más favorable al equilibrio entre la protección a los de- 
rechos de autor de los titulares y el derecho de acceso a la cultura del público.

Y no sólo puede colaborar con el público, pues incluso podemos señalar que el acceso remoto a la colección de la biblioteca conlleva mayor seguridad a la hora de evitar las reproducciones ilícitas de las obras, toda vez que el control arbitrario que se puede implantar en el código de la red y del software permite condiciones de seguridad muchísimo más altas que cualquier control analógico.

La presente conclusión, sumada al hecho de que la norma no limita la clase de biblioteca beneficiaria más allá de prohibirle tener fines lucrativos, genera que las posibilidades de la norma sean realmente favorables para los usuarios de estas instituciones, pues incluso los que utilizan bibliotecas virtuales podrían aprovechar la norma. Es menester señalar que en todos los casos se deben cumplir los requisitos y supuestos que ésta impone, pues no podemos olvidar en ningún caso de que se trata de una excepción y no puede conllevar daños injustificados para los autores ni titulares.

Finalmente, la veracidad y la certeza de nuestras afirmaciones sólo se conocerán con seguridad cuando algún tribunal de la República con competencia en un caso como éste pueda fallar respecto a las ideas que aquí planteamos en el supuesto de que sean esgrimidas como argumento de la beneficiaria. Hasta entonces, únicamente podemos confiar en que nuestra interpretación de la norma sea lo más acertada y correcta posible, esperando que eventualmente se convierta en un grano de arena en pos del universal acceso a la cultura.

\section{REFERENCIAS}

Álvarez Valenzuela, Daniel (20II). «En busca de equilibrios regulatorios: Chile y las recientes reformas al derecho de autor». International Centre for Trade and Sustainable Development (ICTSD), Documento de Política I2, Ginebra, Suiza.

Antequera Parilli, Ricardo (2000). Propiedad intelectual, derecho de autor y derechos conexos. Ginebra: OMPI.

Biblioteca del Congreso Nacional (2010). Historia de la Ley 20.435, Modifica la Ley $\mathrm{I} 7.336$, sobre Propiedad Intelectual. Santiago: BCN. 
Burrel, Robert y Allison Coleman (2005). Copyright Exceptions: The Digital Impact. Cambridge: Cambridge University Press.

Castro, Joaquín y Vicente Grubsic (20I4). Bibliotecas, bibliotecas virtuales y acceso a la cultura en el marco de las excepciones al derecho de autor de la Ley 17.336. Tesis de licenciatura, Facultad de Derecho, Universidad de Chile.

Chapman, Audrey (200I). «La propiedad intelectual como derecho humano (obligaciones dimanantes del apartado c) del párrafo I del Artículo I 5 del Pacto Internacional de Derechos Económicos, Sociales y Culturales)». Boletín de Derecho de Autor, I5 (3). Disponible en $<$ http://unesdoc.unesco.org/images/oOI 2/oOI 255/I25505s.pdf>.

Crews, Kenneth (2008). "Estudio sobre las limitaciones y excepciones al derecho de autor en beneficio de Bibliotecas y Archivos». Ponencia presentada en la decimoséptima sesión del Comité Permanente de Derecho de Autor y Derechos Conexos, Ginebra, Suiza, 3-7 de noviembre, 2008. Disponible en <http://www.wipo.int/meetings/es/ doc_details.jsp?doc_id= $=$ 6805>.

FernándeZ-Molina, Juan Carlos (2008). «Derecho de autor y bibliotecas digitales: en busca del equilibrio entre intereses contrapuestos». Transinformação (Campinas), 20 (2).

Griffiths, Jonathan (2009). «The 'Three-Step Test' in European Copyright Law: Problems and Solutions». Disponible en <http://papers. ssrn.com/sol3/papers.cfm?abstract_id=I476968>.

InTERnATIONAL Organization fOR STANDARDization (I996). Information Technology. Open Systems Interconnection. Basic Reference Model: The Basic Model ISO/IEC 7498-I. Ginebra: ISO.

Olifer, Victor (2007). Different Flavours of VPN: Technology and Applications. Disponible en <https://www.ja.net/sites/default/files/ Different \% 2oflavours \% 20of \% 20vpn \% 2otechnology \% 20and $\%$ 20 applications.pdf>.

Satanowsky, Isidro (I954). Derecho intelectual. Buenos Aires: Tipográfica Editora Argentina.

Sirinelli, Pierre (I999). «Excepciones y limitaciones al derecho de autor y los derechos conexos». Conferencia presentada en el Taller sobre Cuestiones de Aplicación del Tratado de la OMPI sobre Derecho de Autor (WCT) y el Tratado de la OMPI sobre Interpretación o Ejecución y Fonogramas (WPPT), Ginebra, Suiza, 6 y 7 diciembre. 
Smith, James E. y Ravi NaIR (2005). Virtual Machine. Versatile Platforms for Systems and Processes. San Francisco: Morgan Kaufmann. Tanenbaum, Andrew S. (20II). Computer Networks. Boston: Pearson Prentice Hall.

Walker, Elisa (20I4). Manual de propiedad intelectual. Santiago: Legal Publishing.

\section{SOBRE LOS AUTORES}

Vicente Grubsic Lavín y Joaquín Ignacio Castro Martínez son, respectivamente, egresado y estudiante de Derecho de la Facultad de Derecho de la Universidad de Chile. Sus correos electrónicos son <vicentegrubsic@u.uchile.cl> y <castro@ug.uchile.cl>. Su dirección postal es Portugal 48, departamento 22I, Santiago.

Este trabajo fue recibido el I 6 de enero de 20 I 4 y aprobado el 22 de enero de 2015 . 
